\title{
Talking about the Responsibility of Media in Guiding Public Opinion under the Network Environment
}

\author{
Ting-Ting $\mathrm{XU}^{1, \mathrm{a}}$, Han $\mathrm{LIU}^{2, \mathrm{~b}}$, Jing $\mathrm{HU}^{3, \mathrm{c}}$ \\ ${ }^{1,2,3}$ School of Arts and Communications, Wuhan Polytechnic University, Hubei, China \\ a13971606074@163.com,b1515597385@qq.com,,343924723@qq.com
}

Keywords: Internet environment, Public opinion, Media.

\begin{abstract}
The development of Internet technology promotes the growing popularity of Internet applications. The relatively free and open network environment makes mass communication pattern changed. Wide sources of information, fast speed of transmission and the boost of the public free speech cause the public "to jump" from the traditional dissemination environment, and at an all-time high participation, giving rise to "viral" spread and "Communicator and audience in one" mode of transmission. In this case, how to guide the network public opinion, make the network media in the new environment bare right responsibility of public opinion direction, has become a current hot topic.
\end{abstract}

\section{The Analysis of Current Network Environment in China}

"35th China Internet Development Condition Statistics Report" of CNNIC has suggested that 54.5 percent of netizens have faith in the Internet in2014, the credibility of the netizens have improved greatly compared to 35.1 percent in 2007. The investigation indicated that $43.8 \%$ netizens like making commentaries on the Internet. Network space has become an important place of speech. From the overall environment, the massive network information, the fast dissemination speed, the free access to information, and the relatively open environment, accustomed public to obtaining or releasing information on the network and having high credibility about it, "the communication with fingers" become more and more frequent. Compared to the traditional communication environment, the network communication environment has following characteristics.

\section{Civilian of Voice}

The development of network technology provides an opportunity and platform to speak for public; the rising of public awareness prompted the nationals to begin expressing opinions. In that open platform, voice is no longer controlled by media, but also by general public, their comments will also be taken seriously.

\section{"Grassroots" Opinion Leader}

The inclusive of network influence the netizens. People's ideas are more and more active, and they are more willing to absorb the views of others. Unlike the traditional environment, the interactive between media and public enhances in the network environment, so does it among the public. The spokesman approved widely may become the leader in some specific region.

\section{The Upgraded Version of the "Agenda Setting"}

The main meaning of the agenda setting theory is that, the cognition of audience about the importance of these issues will be affected if the mass media increase the amount of some issues or highlight them. Now, with the increased access to information the audiences have rights to choose information. And, with the development of network technologies, they can also publish information. Therefore, some scholars put forward that the social public using the network stated the fact or expresses the opinion, by each kind of different dissemination form, which has aroused the widespread attentions, we called it the self-agenda setting of public."( As shown in Fig 1) 


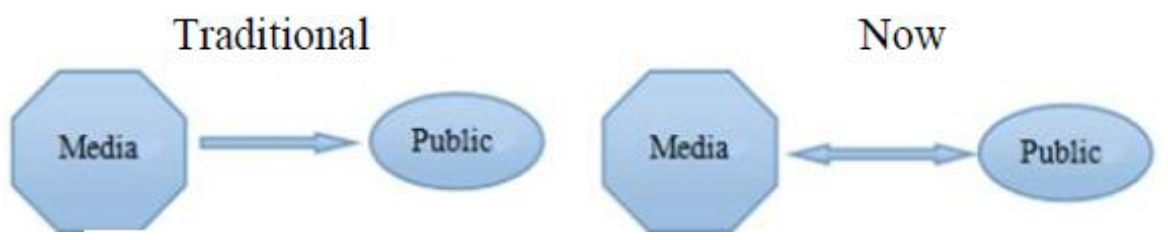

Fig 1 Traditional and modern modes of transmission

\section{The Importance of Network Public Opinion}

"Public opinion is the sum of belief, attitudes, opinions and emotional expression about various phenomena and problems from the public, where rational and irrational ingredients mixed", thought Professor Chen Lidan. The network public opinion refers to the public opinion which disseminates through Internet.

The basic conditions for the formation of public opinion are freedom of speech and debate. The freedom and interaction of internet provide an ideal "incubators" for the production and dissemination of public opinion"However, many unharmonious factors also exist in the network environment. The wrong guidance of public opinion can make these disharmonious factors bigger and bigger like rolling a snowball, which brought very serious adverse effects.

Whether the guidance of the network public opinion is correct decides the health of the network environment. The amount of Chinese netizen is huge; they have different hierarchy in ages, cultural levels, personalities and ethical standards. The healthy network environment has great significance to the individual development of netizen. In addition, the correct guidance of public opinion is of great significance on the stability of society, resolution of social conflicts, and promotion of social harmony.

\section{The Responsibility of Media in Guiding Public Opinion under the Network Environment}

The news media, a tool of news carrier and the formation of public opinion, receives the expectation from public, which has the inseparable relation with the democratic politics. All sorts of pressures request the media to serve for the public and undertake the social responsibility in guiding public opinion correctly. The media should put the self-discipline in the first place, what's more, focus on the improval of professional level, professional ethics, and the cultivation of social responsibility ( As shown in Fig 2) .

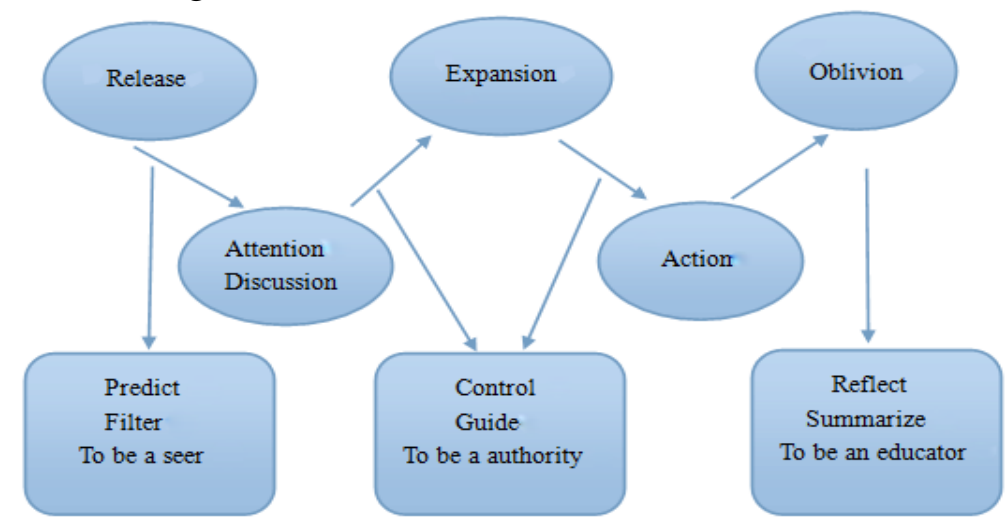

Fig 2 The responsibility of the media

\section{To Be a "Seer"}

In the network environment, once the network public opinion develops, it is hard to control. Therefore, the media should develop a higher sensitivity to public opinion, pay close attention to network information, analyze the public psychology deeply and be farsighted. Only in this way, will it own certain ability of judgment about the production and trend of public opinion. Once some signs found, the media should react quickly, and control the public opinion from the source. Take "the 
robbery of salt" events in 2011 for example, part of Chinese public felt panic when the magnitude-9 earthquake in Japan triggered a nuclear leak. However, when the media widely reported in the earthquake disaster, most of the media ignored the panic of the public from the nuclear leakage. There was also no adjustment to the public "irrational panic". In the mass moment of anxiety, "salt" rumors on the Internet is rising, which bring terrible impacts, fears of nuclear contamination caused that many people rushed to purchase salt, which had brought the enormous negative influence to the society.

\section{To Be An "Authority"}

The media insist the dissemination idea of objective and real, only then will they have credibility and thus authoritative and a powerful voice in order to play a vital role in guiding the public opinion. It is the effective way to enhance the media credibility that the media associates with each other and get help from each other. it is difficult to tell the truth for the netizens because of the freedom of speech, wide channels of information. Meanwhile, the qualities of the netizens are various, which leads to intensified rumors and the illusion of chaos. At this time, a speech from an authority is urgent.

In March, 2015, the false news "Singapore founding Prime Minister Lee Kuna Yew passed away" ignited online. The major Chinese and foreign media are rushing to reprint the article in pursuit of timeliness without verifying the news.

When this news was confirmed as fake news, Netizens were shocked. False news hit several influential foreign media outlets and even on the headlines. This incident has greatly reduced the authority of the media, but also sounded a warning to the media. Pursuit of timeliness is required for profession, but we cannot ignore the essence of news authenticity. At the same time, in this case, we can see the importance of the authority of the media. When false news is overwhelming, because of the clarification of official media and apology of major media, the situation reversed within one hour. The media must have a sense of responsibility from the matter. It is of great significance to the guidance of public opinion that the media must follow the profession criterion in the complex network environment, and set up the authoritative image.

\section{To Be An Educator}

According to the agenda-setting theory, the media can influence the audience awareness of the importance of the problem. At present the network information is numerous and diverse, the media should have a criterion in heart, and regard the right public opinion direction as behavior objectives and standards. Actually undertake the responsibility of education in the network environment. In addition, they must strive to promote the kindness and transmits the energy and gradually create a healthy Internet environment. For example, in March 2014, an article on "hold fire man" came from micro-blogging, which aroused widespread concern in society because of so many reports from media. The responsibility and dedication conveyed by the man has moved general netizens and received countless accolades and acclaim. It actually indicates the education function of news when the media cover such news. In addition, using authority to popularize the relevant knowledge in the transmit process of public opinion, or analyzing and evaluating after dealing with it are also the educational responsibilities of the media.

\section{Summary}

Moreover, in order to safeguard netizens ' right to know well, increase the benign interaction between the netizens and the media. We look forward to the establishment of a new, more convenient, transparent and authoritative platform------a dedicated news search engine. Netizens will be free to ask questions, search the news you want to know about the truth, or their background. Unlike existing engines, it is controlled by the media. The publisher of information, are not all netizens, but media workers who are expert and professional. According to the questions of the netizens, the platform responds in a timely manner after the investigation to meet the information needs of users. Meanwhile, 
the search engine understands and grasps the public opinions in a timely manner with the collation and analysis of relevant information.

The Complex network environment increases the difficulty for the media in shaping public opinion. However, the "correct guidance of public opinion, is the party and the people's blessing; a wrong direction of public opinion, is the disaster of party and people" The media must be responsible for the society and people, practically in the guidance of public opinion. In order to build a healthy network environment, stable and harmonious social environment, the media must be a "Seer", an "authority" and "an educator", make good use of the network technology to achieve innovations and breakthroughs.

\section{References}

[1] Mc Quail's, Mc Quail's mass communication theory.(Fifth edition) ,Beijing,2010.

[2] Ma Zhenfei, The directive tutorial of network public opinion, Beijing, 2014.

[3] Tong Bing, Chinese Journalism and Communication Studies, The latest report, Shanghai, 2010.

[4] Yu Xiucai, The network public opinion: origin, evolution and guidance, Beijing, 2012.

[5] Chen Lidan, Public opinion study------guidance of public opinion, Beijing, 1999.

[6] Guo Qingguang, The directive tutorial of Communication, Beijing, 2011.

[7] China Internet Network Information Center, The 35th statistical report on Internet development in China.

[8] Pan Zhiyong Chen Aiguo, alienation of the news planning, News hype,1999.

[9] Wen Feng, what is the essence of the news,2008.

[10] Jiang Zeming, The 17th plenary session of the CPC report,2011. 